\title{
JOURNAL.RU
}

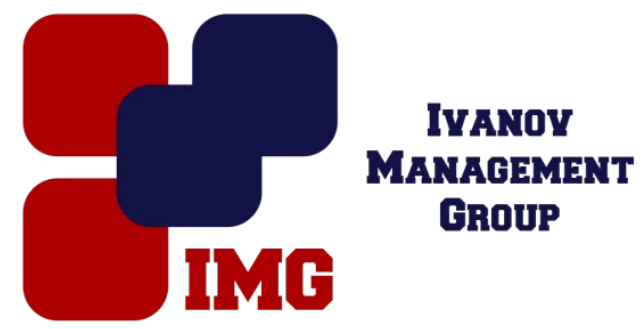

Баженов Ю.В.

Кубанский государственный Технологический университет

Краснодар, Россия

doi: 10.18411/lj-31-01-2017-2-02

idsp 000001:lj-31-01-2017-2-02

\section{Методологическиеаспекты к представлению сущности понятия «конкуренция»}

\section{Аннотация}

Рассмотрены структурный, поведенческий и функциональный подходы к сущности понятия«конкуренция». Выявлены методологические аспекты статического и динамического подходов к сущности данного понятия. Обозначены экономические школы, трактующие сущность конкуренции в рамках статического и динамического подходов

Ключевые слова: структурный, поведенческий и функциональный подходы,динамический подход, конкуренция, методологические аспекты, статический подход

Различные точки зрения экономистов при исследовании объекта необходимо в том случае, когда исследуемый объект является сложным экономическим явлением или процессом, и в научной среде нет сложившегося общепринятого определения объекта исследования [1]. Различные методологические аспекты к представлению сущности понятия «конкуренция» влияют на методические подходы к оценке конкурентоспособности [2]. Конкуренция является одной из исходных категорий, характеризующих сущность рыночной экономики[3,с.401].Под конкуренцией (от лат. concurrentia сталкиваться) понимается соперничество на каком-либо поприще между отдельными юридическими или физическими лицами (конкурентами), заинтересованными в достижении одной и той же цели [4, c. 10].

Существование нескольких методологических подходов к сущности понятия «конкуренция» обусловлено как постоянным развитием мировой экономической науки, так и существованием в ней разных экономических школ одновременно. Между тем, разработка концепции конкуренции, адекватно отражающей развитие конкурентных отношений в экономике, имеет как теоретическую, так и практическую ценность[5]. 
Наибольшее распространение в экономической науке получила типология подходов к конкуренции, которая выделяет структурный, поведенческий, функциональный подходы [6]. Остановимся кратко на характеристикевышеуказанных подходов. Преобладающим подходом к пониманию сущности и к оценке состояний конкуренции является структурный подход.Он основывается на современной теории морфологии рынка. Структурный подход позволяет выработать критерии и подходы к оценке состояний конкуренции, обеспечивающие государственное вмешательство в ход развития конкуренции на рынках. При этом конкуренция рассматривается как состояние рынка, при котором число фирм, продающих однородный продукт, должно быть настолько велико, а доля конкретной фирмы на рынке настолько мала, что никакая фирма одна не может повлиять на цену товара путем изменения объема своих продаж [7]. Наиболее отчетливо структурный подход к пониманию сущности конкуренции прослеживается в работах Э. Чемберлина, Дж. Робинсон, А. Курно, К. Менара, В. Ойкена, Ф. Эджоурта, А. Юданова и других $[8,9,10,11]$. Именно сторонники структурного подхода заложили и развили основы представлений о современной западной теории четырех основных типов рынков: совершенной конкуренции, монополистической конкуренции, олигополии и монополии. В основу классификации рынков структурным подходом положены различные критерии. К наиболее распространенным относят число участников рынка, численность продавцов, характер продукта, доля фирмы на рынке и т.д. [12].При данном подходе основное внимание уделяется анализу структуры рынка по составу участников и их долям. Поведенческий подход определяет конкуренцию только как состязательность на рынке[13]. Он основан на обыденном понимании конкуренции как соперничества за лучшие результаты в какой-либо сфере. Идеи поведенческого подхода конкуренции были развиты представителями неоклассической школы: А. Маршаллом, Г. Муром, У. Джевонсом, П. Хейне [3, $9,14,15]$. Они рассматривали конкуренцию как борьбу за ограниченное количество экономических ресурсов и особенно - за деньги потребителя, на которые их можно приобрести. Поведенческая интерпретация конкуренции прослеживается и в работах М. Портера, который рассматривает поведение конкурирующей фирмы в двух аспектах выгодного распределения ресурсов: сокращения издержек и дифференциации свойств продукта [16]. При этом неизбежность влияния внешней среды оценивается им как фактор, определяющий состояние конкуренции.Функциональный подход рассматривает конкуренцию как обязательный элемент рыночного механизма, который направлен на устранение отклонений от нормального развития экономики. Сущность конкуренции проявляется через реализуемые ею функции. Функциональный подход представлен трудами Й. Шумпетера и Ф. фон Хайека $[17,18]$.

В целом все вышеперечисленные подходы исходят из одинакового видения сущности и экономической природы конкуренции[19]. Такое видение 
исходит из теории рыночного равновесия и трактует конкуренцию как состояние рынка, которое можно измерить при помощи математических расчетов. Ученые экономисты при таком видении конкуренции рассматривают срез конъюнктуры рынка на текущий момент и оценивают расклад сил среди участников рынка [20]. Недостатком типологиивышеперечисленных подходов является замалчивание динамической природы конкуренции.

Однако существует и другое видение сущности и экономической природы конкуренции, которое представлено в рамках австрийской экономической школы. Представители этой научной школы О. Бём-Бавёрк, Л.Мизес, К. Менгер, И. Кирцнер, Х. Уэрта де Сото, М. Ротбардпредставляют экономическую сущность конкуренции иначе [20, 21, 22, 23, 24]. Природу экономической конкуренции они видят не в соперничестве участников рынка за ограниченные ресурсы, а в недостаточной информированности рыночных агентов по поводу использования ими рыночных возможностей. С точки зрения австрийцев, конкуренция представляет собой динамический процесс соперничества, а не так называемую «модель совершенной конкуренции», в которой многочисленные участники делают одно и то же и все продают по одинаковой цене, так что парадоксальным образом складывается ситуация, в которой никто не конкурирует [24].Анализируя статическую модель конкуренции, Ф. фон Хайек утверждает, что совершенная конкуренция оказывается лишь одной из возможных точек реального конкурентного процесса, а вовсе не единственной и не детерминированной[17].

По нашему мнению, точка зрения ученых, принадлежащих к австрийской экономической школе и рассматривающих конкуренцию как динамический процесс открытия информации об имеющихся рыночных возможностях, недостаточно представлена в современной экономической науке. Более того, при типологизации подходов к пониманию сущности конкуренции на структурный, поведенческий и функциональный, точка зрения сторонников теории динамической конкуренции не является значимой ни в одном из подходов [25]. Справедливо заметив, что хотя взглядыФ.фонХайека рассматривается в рамках функционального подхода, однако понимание сущности конкуренции Ф.фонХайеком упрощается к сведению конкуренции как функции рыночной экономики [26].

Учитывая недостатки имеющейся типологии, нами предлагается выделить динамический и статический подходы к пониманию сущности и экономической природы конкуренции. Мы считаем, что при статическом подходе конкуренция отражает сложившееся состояние рынка и характеризует набор рыночных условий, в которых протекает конкурентная борьба [27]. Статическая модель конкуренции предполагает противопоставление конкуренции и монополии как двух полярных состояний рынка. Статическая конкуренция в большей мере присуща структурному подходу к анализу конкуренции и в меньшей мере остальным двум подходам [28, 29]. 
Динамический подход предполагает, что конкуренция является процессом развития рынка. Она представляет собой эндогенную составляющую рыночной среды, которая обусловливает характер изменения рынка и фирм. Понимание динамического характера конкуренции позволяет признать постоянно меняющееся многообразие соотношений конкуренции и монополий как соотношений, проявляющихся в различных вариантах рыночной власти конкуренции между производителями дифференцированного продукта и ценовой дискриминации.

В рамках статического подхода к пониманию сущности и экономической природы конкуренции мы предлагаем учитывать следующие характеристики. Источником конкуренции является общее экономическое равновесие на рынке. А так как любые ресурсы имеют всегда ограниченный характер, то участники рынка вступают в противоречия между собой, и указанные противоречия являются движущей силой конкуренции. Сущность конкуренции представляется как определённое состояние дел на рынке. Функциями конкуренции являются: эффективное распределении ресурсов по отраслям; обеспечение эффективности производства; обеспечение максимально возможного благосостояния общества. Действие конкуренции проявляется через механизм взаимодействия спроса и предложения на рынке. Результатом конкуренции является оптимальное разделение труда, обеспечивающее эффективность экономики. Конкуренция имеет значение для экономической жизни как особый институт организации бизнеса, оптимизирующий рыночные цены через механизм взаимодействия спроса и предложения в некой точке равновесия. Сторонниками такого подхода являются почти все представители классической и неоклассической школ экономической мысли.

Динамический подход к пониманию сущности и экономической природы конкуренции по нашему мнению усматривает источником конкуренции общее экономическое неравновесие, имманентно присущее рынку. Движущей силой конкуренции в рамках данного подхода является рассогласование и принципиальная ограниченность информации у предпринимателей об имеющихся рыночных возможностях. Сама конкуренция является с точки зрения динамического подхода процессом открытия информации предпринимателями. Функции конкуренции заключаются в выявление и обобщении информации, разбросанной среди множества рыночных агентов и часто имеющей неявный характер; стимулировании поиска новой экономически значимой информации; согласовании действий, направленных на разные цели; организация и координация индивидуальных усилий рыночных агентов. Конкуренция воздействует на рынок через механизм инноваций. Результатом конкуренции является постоянное движение к динамическому равновесию. Конкуренция является движущей силой экономической жизни, которая вносит координацию в рассогласованную жизнь общества. Сторонниками динамического подхода являются представители австрийской экономической школы. 
Предложенная типологияметодологических подходов к представлению сущности конкуренции позволяетувеличить вес взглядов представителей австрийской экономической школы в экономическом дискурсе на современном этапе развития экономической мысли. Также данная типология подходов обращает большее, чем в существующих на настоящий момент типологиях, внимание на динамическую природу конкуренции, а также предлагает рассматривать конкуренцию не только как явление, но и как процесс.

Выводы:

1. Наибольшее распространение в современной экономической науке получила типология подходов к конкуренции, которая выделяет структурный, поведенческий, функциональный подходы. В рамках вышеуказанной типологии учитываются в большей мере мнения ученых-экономистов, стоящих на позиции теории рыночного равновесия, и представляющие конкуренцию как состояние рынка, при котором его участники ведут состязание за ограниченные ресурсы.

2. Недостатком вышеуказанной типологии является такой аспект, что в состав структурного, поведенческого, функционального подходов не включены точки зрения большого количества ученых-экономистов, представляющих конкуренцию как динамический процесс открытия предпринимателями информации о рыночных возможностях.

3. Учитывая недостатки имеющейся типологии, нами предлагается выделить динамический и статический подходы к представлению о сущности конкуренции. Мы считаем, что при статическом подходе конкуренция отражает сложившееся состояние рынка и характеризует набор рыночных условий, в которых протекает конкурентная борьба. Динамический подход к пониманию сущности и экономической природы конкуренции, по нашему мнению, усматривает источником конкуренции общее экономическое неравновесие, а сама конкуренция является с точки зрения динамического подхода процессом открытия информации предпринимателями. 


\section{Литература}

1. Щепакин М.Б., Кривошеева Е.В.К формированию системы управле-ния конкурентоспособностью производственных предприятий в меняющейся рыночной среде / В сб.: Альтернативные пути преодоления глобального экономического кризиса: Материалы междунар. научно-практ.конф. / Под ред. д-ра экон. наук, проф. М.Б. Щепакина. -Краснодар: Изд.КЦНТИ, 2013. - С. 184-193.

2. Shchepakin M.B., Bazhenov Y.V. Nature of economic competition: me-thodological aspect // Sciences of Europe. 2016. № 7 (7). Vol 2. P. 73-77.

3. Маршалл А. Принципы экономической науки; пер. с англ. - М.: Прогресс, 1993. - 416 c. - T. 1 .

4. Азоев Г.Л., Челенков А.П. Конкурентные преимущества фирмы. - М.: Издательство Новости, 2000. - 256 с.

5. Щепакин М.Б. Предпринимательство в трансформирующихся и развивающихся общественно-экономических системах. - М.: Экономическая демократия,2000. - 511 с.

6. Хандамова Э.Ф., Хараджян Л.В. Экономическая природа конкуренции и конкурентоспособности предприятия (корпорации) // Научный журнал КубГАУ. 2012. - №82(08). - C. 965-990.

7. Жигун Л.А., Третьяк Н.А. Методологические основы оценки динамических состояний конкуренции // Современная конкуренция. - 2008. - №4. - С. 18-29.

8. Чемберлин Э. Теория монополистической конкуренции. - М.: Экономика, - 1996. - 350 c.

9. Фролова Т.А. Экономическая теория: конспект лекций. - Таганрог: ТТИ ЮФУ,2009. 229 c.

10. Юданов А.Ю. Конкуренция. Теория и практика. - М.: ГНОМ и Д, 2011. - 304 с.

11. Блауг М.,Эджуорт, Фрэнсис Исидор. 100 великих экономистов до Кейнса. - СПб.: Экономикус,2008. - 352 с.

12. Щепакин М.Б. Предпринимательство как системообразующий фактор переходной экономики:Диссертация на соискание ученой степени доктора экономических наук. Кубанский государственный университет. - Краснодар, 2002. - 370 с.

13. Баженов Ю.В. О концептуальных различиях в понимании сущности и экономической природы конкуренции // Тенденции развития экономики и менеджмента. Сборник научных трудов по итогам международной научно-практической конференции. 2016. № 3. С. 66-68.

14. Хейне П., БоутткеП.Дж., Причитко Д.Л.Экономический образ мыш-ления; пер. с англ. 10-го изд. - М.: Вильямс, 2007. - 544 с.

15. Блауг М., Джевонс, Уильям Стэнли. 100 великих экономистов до Кейнса. - СПб.: Экономикус, - 2008. - 352 с.

16. Портер М. Конкурентная стратегия: Методика анализа отраслей и конкурентов; пер. с англ. - 2-е изд. - М.: Альпина Бизнес Букс, - 2006. - 454 с.

17. Хайек Ф.А. Конкуренция как процедура открытия;предисловие Р.И. Капелюшникова; пер. М.Б.Гнедовского //Международная экономика и международные отношения. 1989. - № 12. - С. 8-13.

18. Шумпетер Й.А. Капитализм, Социализм и Демократия; пер. с англ., предисл. и общ.ред. В.С. Автономова. - М.: Экономика, 1995. - 540 с.

19. Щепакин М.Б., Баженов Ю.В. Об экономической природе конкурен-ции в условиях её обострения // Конкурентоспособность в глобальном мире: экономика, наука, технологии. 2016. № 2. С. 206-212.

20. Бём-БаверкОйген. Критика теории Маркса. - Челябинск: Социум, 2002. - 283 с. 
21. Кирцнер И.М. Конкуренция и предпринимательство; пер. с англ. И под ред. А.Н. Романова. - М. : ЮНИТИ-ДАНА,2001. - 239 с.

22. Менгер К. Избранные работы. - М.: Издательский дом "Территория будущего",2005. $496 \mathrm{c}$.

23. Мизес Л. Теория и история: Интерпретация социально-экономической эволюции. - М.: ЮНИТИ-ДАНА,2001. - 295 с.

24. Уэрта де Сото Х. Австрийская экономическая школа: Рынок и пред-принимательское творчество; пер. с англ. Б. С. Пинскера; под ред. А. В. Куряева. - Челябинск: Социум,2011. -212 с.

25. Щепакин М.Б., Губин В.А.Идентификация параметров сбалансиро-ванной межотраслевой динамической модели экономической системы//Научно-технические ведомости Санкт-Петербургского государственного политехнического университета. Экономические науки. - 2009. - №3(79). - С. 26-35.

26. Щепакин М.Б. Системообразующий фактор устойчивого развития / М.Б. Щепакин, Г.М. Мишулин, Е.А. Кожура. - М.: Изд. АкадемииПромышленной Экологии,2005. $224 \mathrm{c}$.

27. Щепакин М.Б., Томилко Ю.В.Классификация и формы организации отраслевых инновационных кластеров //Новые технологии. - 2012. - №3. - С. 226-230.

28. Щепакин М.Б., Баженов Ю.В. Классификация методологических подходов к представлению сущности понятия «конкуренция» // Экономика и предпринимательство. 2016. № 5. С. 941-945.

29. Щепакин М.Б., Баженов Ю.В. К вопросу о включении экзогенных факторов в методы оценки конкурентоспособности экономических субъектов // Современная экономика России: опора на внутренние резервы и поворот на восток. 2015. С. 48-53. 